\title{
Basrah Journal

\section{EVALUTION OF BILATERAL V-Y ROTATION ADVANCEMENT FLAPS FOR TREATMENT OF FINGERTIP AMPUTATION}

\author{
Jabir Raheem Hameed* and Roaa Hamed Mahmood ${ }^{\circledR}$ \\ *MB, ChB, FICMS, Consultant Plastic and Reconstructive Surgeon, Al-Sadr Teaching Hospital, Basrah. \\ ${ }^{\circledR} \mathrm{MB}$, ChB, Candidate of CABHS, Plastic and Reconstructive Surgery, Al-Sadr Teaching Hospital, \\ Basrah, IRAQ.
}

\begin{abstract}
Fingertip amputation is the most common injury of the upper limb. The goals of treating it are; covering the defect, achieve sensibility, preserving the length of the finger by using durable coverage, obtaining the satisfactory aesthetic appearance and allow the patient for faster return to work.

This study aimed to evaluate the use of bilateral V-Y rotation advancement flaps for the management of fingertip amputations with exposed bones and to assess the functional and aesthetic outcome.

Between January 2017 and August 2018, bilateral V-Y rotation advancement flaps was performed on eleven male patients, average age 32 years, whose fingertip amputation with variable planes and zones. Patients were followed-up for at least 6-12 months.

Twenty two flaps were made on 11 fingers, there was no partial or total flap loss. Patients had neither cold intolerance nor scar hypersensitivity, no obvious hook nail deformity apart of one patient. Because flap have neurovascular bundle inside it, so no change in sensation or perfusion occur postoperatively.

In conclusion, the $\mathrm{V}-\mathrm{Y}$ rotation advancement flap is simple, single stage operation that is optimum for surgical reconstruction of any fingertip injury. It provides a good contour, finger pulp coverage and acceptable appearance.

Keywords: Fingertip. Amputation, Pulpa, V-Y flap, Reconstruction.
\end{abstract}

\section{Introduction}

Tnjuries of the fingertips are very

preserving the length, avoiding joint common occurrence due to domestic and industrial accidents and are among the most common hand injuries encountered in the emergency room and hand surgery ${ }^{1}$.

With the fingertip being the end organ for touch, preserving maximum function is of the utmost important. Sub optimal reconstruction has the potential to significantly impact one's ability to work, thereby causing socioeconomic losses ${ }^{2}$.

The goals of treating fingertip injuries are; to obtain stable wound closure with the optimum recovery of sensibility with stiffness, minimize donor site morbidity and provide an aesthetically acceptable results. rapid return to job ${ }^{3}$. In this study we adopted Nezih sungur et al. technique which included bilateral V-Y rotation advancement flaps for treatment of fingertip amputation ${ }^{4}$.

Classification of fingertip injuries ${ }^{5}$ : This study used Ishikawa fingertip injury classification. The injured zone is divided in to four subzone: subzone I; distal to the midpoint of the nail. subzone II; from the nail base to the midpoint. subzone III; 
from midway of the nail base and DIPJ to the nail base. subzone IV; from the DIPJ to the midway point.

Amputation injuries are also classified as dorsal, transverse, or volar according to the plane of amputation and the condition of the tissue at the injury site that help to determine the best repair technique for these injuries ${ }^{6}$.

Goals of the fingertip reconstruction ${ }^{7}$ : Provide durable coverage, Preserve the length, Preserve sensation, Minimize pain including prevention of neuroma, Minimize donar site morbidity, Maintain joint function, Provide an aesthetically acceptable results.

Numerous flaps have been described for fingertip coverage, the utilization of local flaps leave donor site in morbidity and this must be taken in to account before the flap is elevated. In 1970, Atasoy and associates described the triangular volar "V-Y" advancement flap for reconstruction of the distal pad with preservation of length when bone is exposed. They suggested that the procedure was applicable to most fingertip amputations even in those who has exposed bones. They believed that it is contraindicated in injuries in which there is an oblique flap with palmer skin loss than dorsal skin loss and in situations in which there was extensive skin loss ${ }^{8}$.

In oblique injury, Kutler lateral "V-Y" flap may be used instead of volar "V-Y" Atasoy flap. These are laterally based V-Y flaps advanced around an oblique defect ${ }^{9}$.

Staged flaps involved two stages for completion of the fingertip reconstruction. The most popular staged flaps are; thenar flap and cross finger flap, both are random pattern flaps that does not have a specific blood supply. The thenar flap and the cross finger flap are used for volary angulated fingertip defect when local V-Y advancement flap are not possible . $^{5}$

A number of elegant and ingeniously conceived island flaps have been described for coverage of fingertip amputations. These consist of flaps raised on their neurovascular pedicles, and the advantages includes; the avoidance of prolonged digital immobilization in an uncomfortable position, single staged reconstruction permitting early rehabilitation, introduction of an independent blood supply to provide good soft tissue bed for nerve grafting or repair, satisfactory restoration of a well-padded sensate digital pulp ${ }^{10}$.

Finger defect coverage using tissue perfused by metacarpal artery has become common in the last two decades for thumb tip injury ${ }^{11}$.

\section{Patients And Methods}

This prospective study aimed to treat fingertip amputations by using bilateral $\mathrm{V}-\mathrm{Y}$ rotation advancement flaps. In this study which was started in January 2017 and finished in August 2018, eleven patients with fingertip injuries were included. All patient were males and had history of smoking apart of one. The age of patients ranged between 20 to 52 years, involved digits were: four ring fingers, three middle fingers, two little fingers, and two index fingers. The amputation zones were:- Ishikawa zone III (4 cases), zone II (5 cases), and zone I (2 cases). The amputation plane were:- dorsal oblique (4 cases), transverse (4 cases), volar oblique ( 2 cases), and lateral oblique ( 1 case).

Inclusion criteria: All fingers with fingertip amputation that can be operated, patients with fingertip amputation at Ishikawa zone I,II, and III, flap used in all planes of fingertip amputation (volar oblique, transvers, dorsal oblique, and lateral oblique).

Exclusion criteria: Those patients with Ishikawa zone IV, those patients with associated sever crush injuries in hand, patients who had multiple organ injuries other than hand.

All patients were preoperatively evaluated by history and proper physical examination in the emergency room. Hands $\mathrm{x}$-ray was done to exclude any fracture or foreign bodies. Preoperative 
routine investigations were performed including hemoglobin level and virology screen. All patient received tetanus vaccine in emergency room. Photographs were taken and informed consent was requested in all patients included in this study. The detailed characteristics of patients is shown in table I.

Table I: patient's data.

\begin{tabular}{|c|c|c|c|c|c|c|c|}
\hline Patient & $\begin{array}{c}\text { Age } \\
\text { (years) }\end{array}$ & Gender & $\begin{array}{c}\text { Injured } \\
\text { digit }\end{array}$ & $\begin{array}{c}\text { Mechanism } \\
\text { of injury }\end{array}$ & $\begin{array}{c}\text { Amputation } \\
\text { zone }\end{array}$ & Amputation plane & $\begin{array}{c}\text { Follow-up } \\
\text { (months) }\end{array}$ \\
\hline 1 & 30 & Male & Ring & Crush & III & Dorsal oblique & 12 \\
\hline 2 & 32 & Male & Index & Sharp cut & II & Transverse & 6 \\
\hline 3 & 28 & Male & Ring & Shell injury & I & Volar oblique & 12 \\
\hline 4 & 52 & Male & Ring & Crush & II & Volar oblique & 6 \\
\hline 5 & 27 & Male & Little & Crush & II & Lateral oblique & 7 \\
\hline 6 & 46 & Male & Ring & Crush & II & Dorsal oblique & $\mathbf{6}$ \\
\hline 7 & 25 & Male & Middle & Sharp cut & I & Transverse & $\mathbf{8}$ \\
\hline 8 & 35 & Male & Middle & Crush & III & Dorsal oblique & 4 \\
\hline 9 & 23 & Male & Little & Sharp cut & III & Dorsal oblique & 9 \\
\hline 10 & 20 & Male & Middle & Crush & III & Transverse & 6 \\
\hline 11 & 37 & Male & Index & Crush & II & Transverse & $\mathbf{9}$ \\
\hline
\end{tabular}

Operative Technique: All operations were done under local anesthesia in form of digital block using $1 \%$ xylocaine without epinephrine. About 2-3 mls of xylocaine was injected around the digital nerves of the finger at the level of distal palmer crease volary, and dorsally over the extensor hood. By using sharp scissor or No.15 scalp blade, all devitalized tissues were completely excised, and any sharp spikes of bone were trimmed. The defect was measured and a rubber tourniquet was applied to the proximal part of the finger. By methylene blue marking, we first drew a longitudinal line from mid of the defect and imaginary extension up to the flexor crease of the distal interphalangeal joint, this line will divide the distal phalanx into two halves. Each half at flexor crease of distal interphangeal joint was subdivided into another halves by drawing quarter points.
The V-Y rotation advancement flaps were planed bilaterally on volar aspect of the remaining distal phalanx. First the long limb of "V" is drawn from mid of the defect and extended in tangential way to midline, then it curve toward the quarter point. The short limb of "V" is drawn from the quarter point to the half distance of remaining fingertip's mid lateral point as shown in figures 1 and 2. If more tissue is needed, short limb could be made from finger's volar lateral line to the dorsal lateral line. The limbs of "V" were planned in a slight convex shape so that it will include both the proper digital artery and nerve with in a flap, same marking then was repeated on other half of remaining distal phalanx. The base of flap was designed to be equal to the half of the defect.

The total operative time ranged from 25 to 35 minutes with an average of $28 \mathrm{~min}$. 


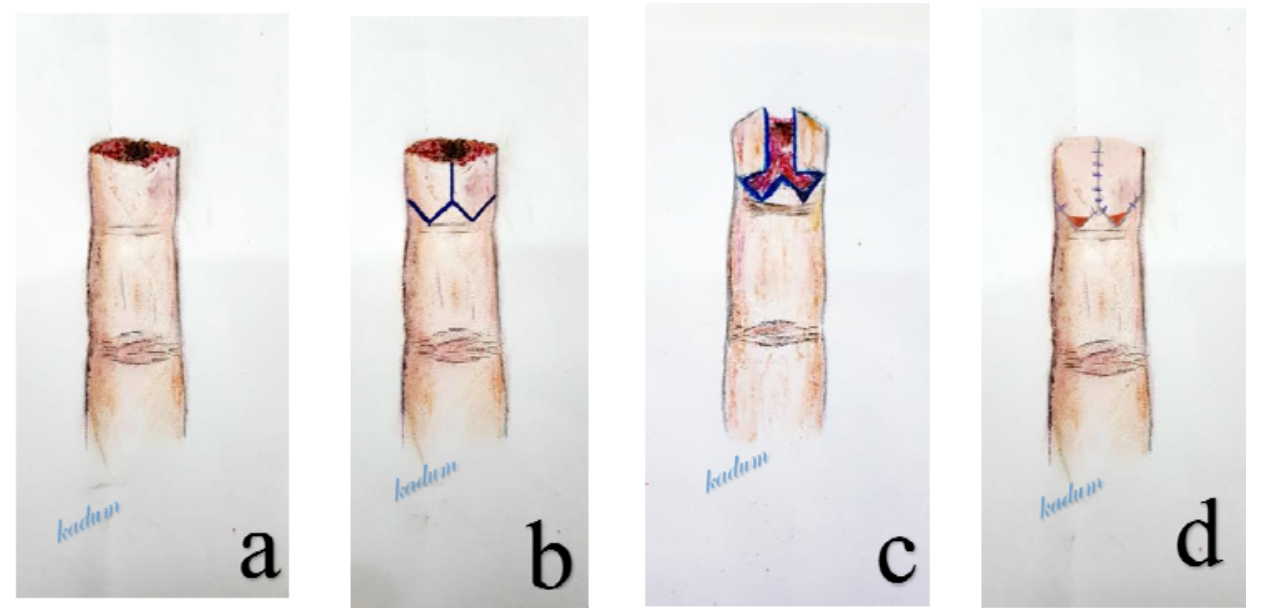

Figure 1: Illustration of fingertip reconstruction with V-Y rotation advancement flaps. a: Ishikawa zone II, transverse fingertip amputation. b: design of $\mathrm{V}$ shaped flaps. c: rotation and advancement of flaps. d: Y shaped closure of the flaps.
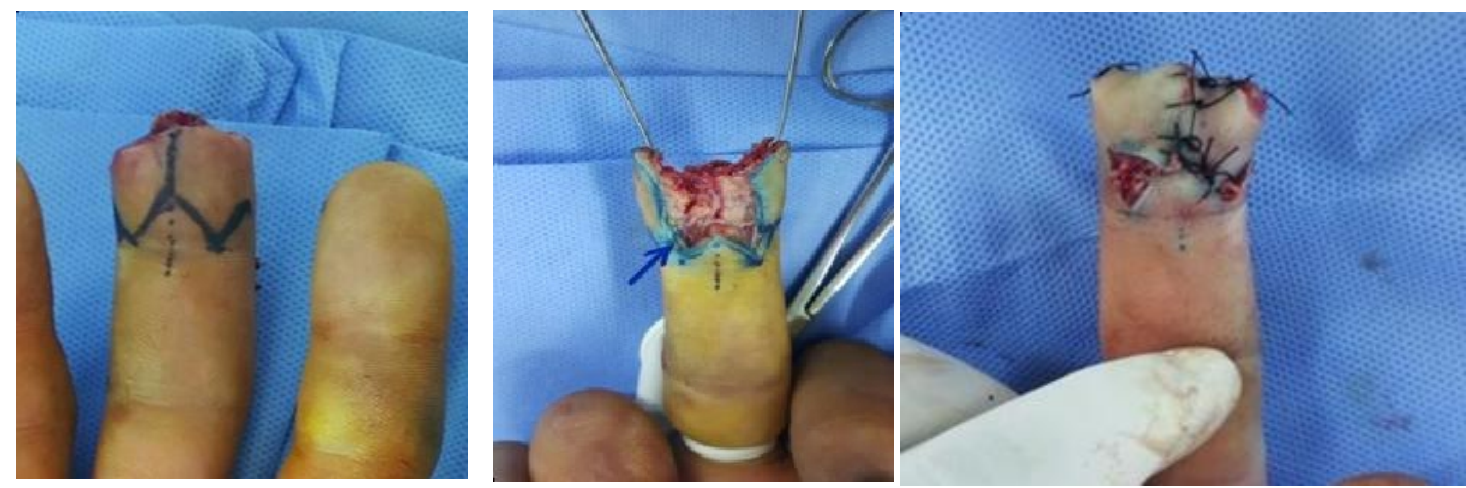

Figure 2: Steps of V-Y rotation advancement flaps

Patients were kept on injectable first generation cephalosporine in the first postoperative day, and then continued with oral antibiotics for 7 days postoperatively. They were discharged at the same day of operation and instructed to keep hand elevated, dressing changed daily and the sutures were removed on the $10^{\text {th }}-14^{\text {th }}$ day and were instructed about follow-up for at least 6-12 months postoperatively.

\section{Results}

Eleven patients presented with fingertip injury with various amputation planes and various amputation zones were included. The dimensions of the defect ranged from $(1.5 \times 1)$ to $(2 \times 1.8) \mathrm{cm}$ and the average was $(1.75 \times 1.4) \mathrm{cm}$. The unilateral flap dimensions ranged from $(1.5 \times 0.7)$ to
$(2 \times 0.9) \mathrm{cm}$ and the average was $(1.75 \times 0.8) \mathrm{cm}$.

Bilateral V-Y rotation advancement flaps revealed $100 \%$ of the viability without any flap necrosis. The two points discrimination test was done and the static two points discrimination test in the flaps ranged from 3 to $6 \mathrm{~mm}$, with a mean of $4.7 \mathrm{~mm}$, compared with the range from 3 to $5 \mathrm{~mm}$, with a mean of $3.3 \mathrm{~mm}$ of the contralateral hand for the equivalent site. The mobile two points discrimination test in the flap ranged from 3 to $6 \mathrm{~mm}$, with a mean of 4.09 , compared with the range from 2 to $4 \mathrm{~mm}$, with a mean of $2.7 \mathrm{~mm}$ of the contralateral side, all digits were sensate to light touch and pinprick. The healing time ranged from 10-14 days, with a mean of 11.4 days. The average time to return to their work was 3-4 weeks 
without any complaining. Regarding the results of the residual pain it was; no pain in $90.9 \%$, and mild pain with tapping $9.09 \%$. No cold intolerance in all patients (table II). No joint stiffness, neither functional impairment was noticed in all our patients and full range of movement was achieved postoperatively both in proximal and distal interphalangeal joints.

The questioner results about patient satisfaction regarding functional results was $45.4 \%$ patients rated their result as excellent, $36.3 \%$ patients as good, $18.1 \%$ patients as fair, $0.0 \%$ as poor. In respect to sensibility $72.7 \%$ patients rated their results as excellent, $18.1 \%$ as good, $9 \%$ as fair, $0.0 \%$ as poor. In respect to appearance, $9 \%$ patients rated their results as excellent, $27.2 \%$ as good, $36.3 \%$ as fair, $27.2 \%$ as poor (table III). No obvious nail deformity was seen in patients with digital amputation distal to Ishikawa II, except in one patient who developed parrot peak nail deformity which required revision surgery later on. No postoperative infection, hematoma, or wound dehiscence was seen in all our patients, apart from one patient who developed epidermal loss at the junction site of the two flaps, this patient was treated conservatively without any sequelae. mild flexion deformity at DIP joint was noticed in one patient and that did not affect the function. No abnormal ugly volar scar was noticed in all of our patients.

Table II: results of bilateral V-Y rotation advancement flaps and its complication.

\begin{tabular}{|l|l|l|l|l|l|l|l|}
\hline $\begin{array}{l}\text { Patient } \\
\text { No. }\end{array}$ & $\begin{array}{l}\text { Flaps } \\
\text { Viability }\end{array}$ & $\begin{array}{l}\text { Flap S2PD Sensibility } \\
(\mathrm{mm})\end{array}$ & $\begin{array}{l}\text { Flap M2PD } \\
\text { Control S2PD } \\
(\mathrm{mm})\end{array}$ & $\begin{array}{l}\text { Control } \\
(\mathrm{mm})\end{array}$ & $\begin{array}{l}\text { Healing } \\
\text { Time (days) }\end{array}$ & $\begin{array}{l}\text { Residual } \\
\text { pain }\end{array}$ \\
\hline 1 & Viable & 6 & 3 & 4 & 3 & 11 & No \\
\hline 2 & Viable & 4 & 3 & 3 & 2 & 10 & No \\
\hline 3 & Viable & 6 & 4 & 4 & 3 & 14 & No \\
\hline 4 & Viable & 5 & 3 & 4 & 3 & 12 & Yes \\
\hline 5 & Viable & 4 & 3 & 4 & 3 & 10 & No \\
\hline 6 & Viable & 4 & 3 & 4 & 2 & 11 & No \\
\hline 7 & Viable & 3 & 3 & 3 & 2 & 10 & No \\
\hline 8 & Viable & 6 & 4 & 6 & 3 & 14 & No \\
\hline 9 & Viable & 6 & 5 & 5 & 4 & 13 & No \\
\hline 10 & Viable & 4 & 3 & 4 & 2 & 11 & No \\
\hline 11 & Viable & 4 & 3 & 4 & 3 & 10 & No \\
\hline
\end{tabular}

Table III: Patient satisfaction (Questioner result).

\begin{tabular}{|l|l|l|ll|ll|}
\hline Category & Excellent & Good & \multicolumn{2}{|l|}{ Fair } & \multicolumn{2}{|l|}{ Poor } \\
\hline Function & $5(45.4 \%)$ & $4(36.3 \%)$ & 2 & $(\mathbf{1 8 . 1 )}$ & 0 & $\mathbf{( 0 . 0 \% )}$ \\
\hline Sensibility & $\mathbf{8}(72.7 \%)$ & $2(18.1 \%)$ & 1 & $\mathbf{( 9 \% )}$ & 0 & $\mathbf{( 0 . 0 \% )}$ \\
\hline Appearance & $1(9 \%)$ & $3(27.2 \%)$ & 4 & $(36.3 \%)$ & 3 & $(27.2 \%)$ \\
\hline
\end{tabular}

The following figure shows some samples of the outcome of this type of surgery. 

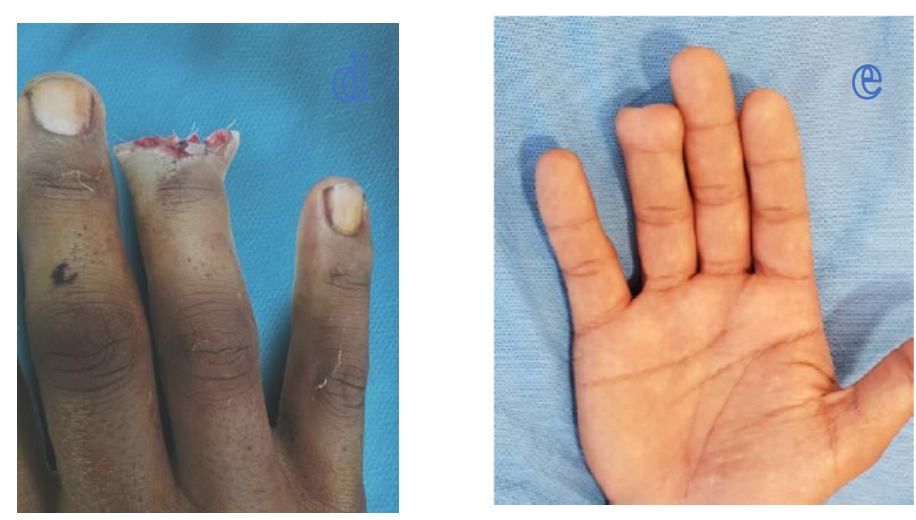

Sample 1
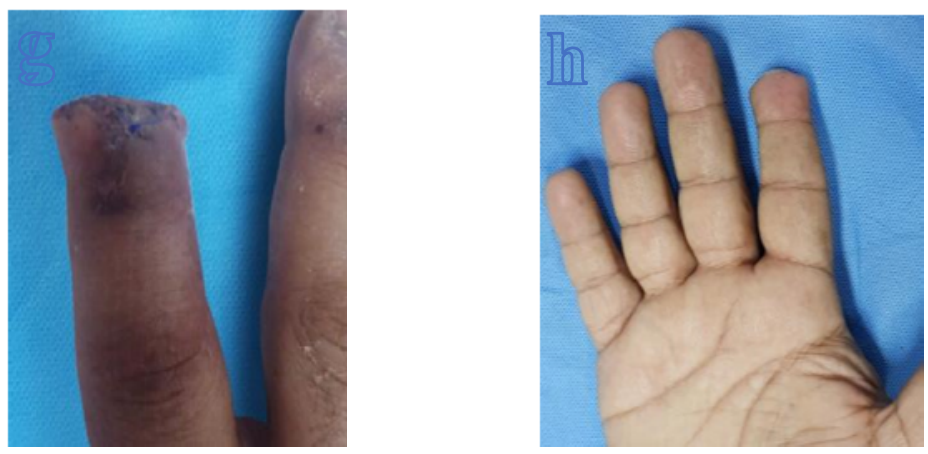

Sample 2
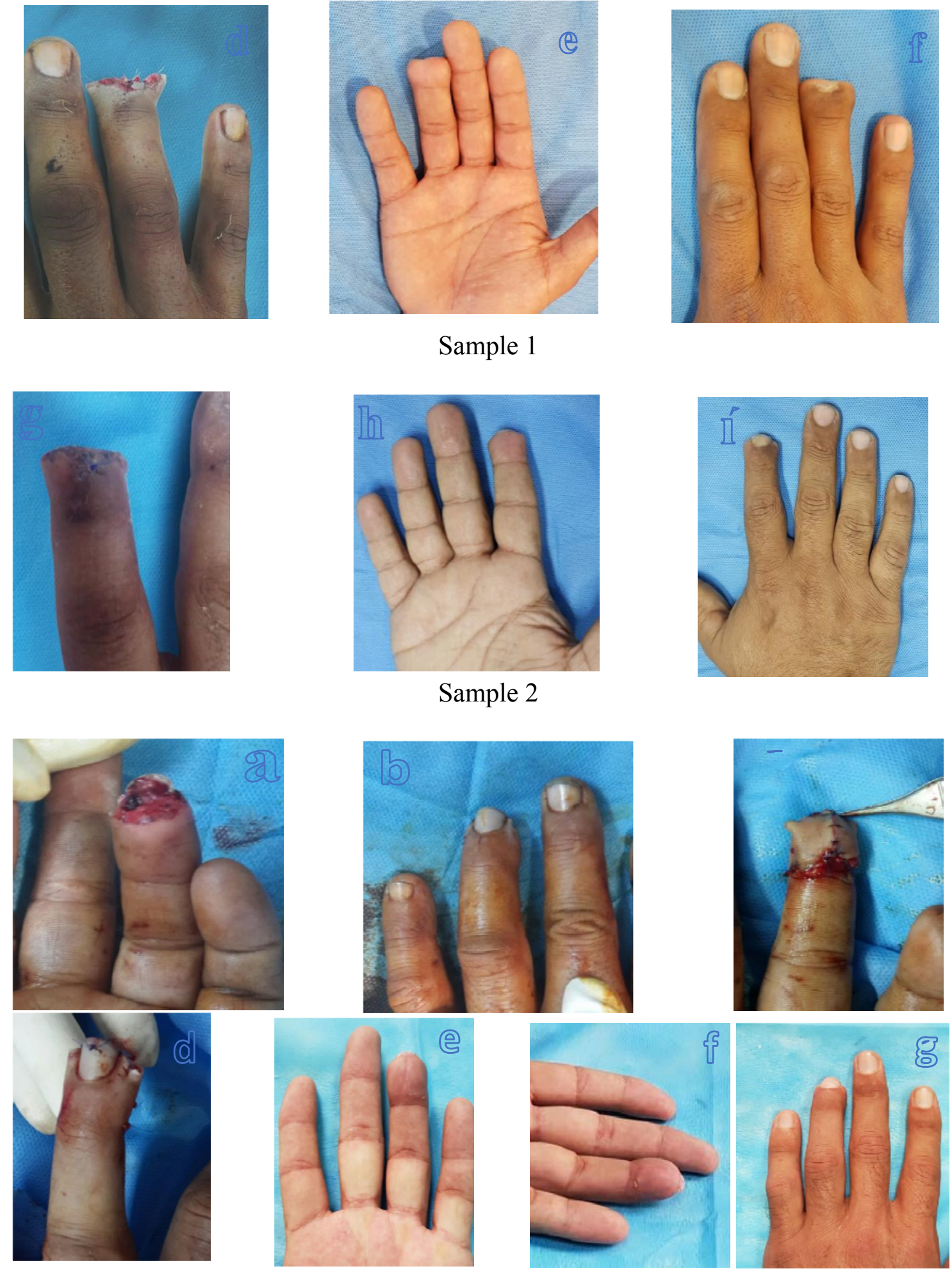

Sample 3

Figure 3 : Samples of final results

\section{Discussion}

Hand injuries constitute the single most frequent surgical presentation in an average emergency department ${ }^{12}$. A stable, mobile and well sensate fingertip is important to the overall perfect functions of the hand. In addition, the faces and hand are the most looked at parts of our body. When faced with fingertip injury, 
clinicians will need to manage both functional and aesthetic consideration in their proposed treatment strategy ${ }^{13}$.

In this study 11 patients presented with history of fingertip injuries were surgically treated by using bilateral V-Y rotation advancement flap. This flap was used for various amputation planes (dorsal oblique, transverse, volar oblique, and lateral oblique) with different amputation zones (Ishikawa zone III, zone II, and zone I). The average dimension of the defect was $(1.75 \times 1.4) \mathrm{cm}$.

Our results were functionally and aesthetically accepted and are consistence with Nezih sunger et $\mathrm{al}^{4}$. who used bilateral V-Y rotation advancement flaps for treatment fingertip amputation on 7 fingers and they achieved excellent results both functionally and aesthetically in all of their patients.

Atasoy and associates, in 1970 described triangular V-Y advancement flap for distal fingertip injury ${ }^{10}$. Atasoy flap is subcutaneous pedicle flap that received its blood supply from oblique terminal branches of digital artery arising from trifurcation at the distal interphalangeal joint ${ }^{5}$. This flap is indicated for transverse or dorsal oblique injury to the fingertip beyond the mid part of the nail, and its contraindicated for oblique amputation with more palmer skin loss than dorsal skin loss. In addition to that, Atasoy flap cannot be used for larger defect since it achieved up to $1 \mathrm{~cm}$ advancement so that it is just used for defect $\geq 1 \mathrm{~cm}^{10}$.

In order to avoid above mentioned problem that associated with Atasoy volar V-Y advancement flap, a new modification was used, this modification includes using of bilateral $\mathrm{V}-\mathrm{Y}$ rotation advancement flaps. This modification allow to use such flap in various amputation planes, also because this flap is rotated during advancing, this leads to more advancement which enable us to close more than $1 \mathrm{~cm}$ defect. When more tissue is needed, the short limb of "V" can be extended from volar mid lateral line to dorsal line.

$\mathrm{V}-\mathrm{Y}$ rotation advancement flaps are well vascularized so that we didn't encountered any case with flap necrosis. In our aim, the limbs of "V" were designed in convex manner in order to include the digital artery and nerve with in the flap. Presence of digital artery within this flap increases its survival and decreases risk of flap necrosis. V-Y rotation advancement flap can be regarded as an axial pattern flap. Presence of digital nerve with in this flap, enable patient to regain their sensation with excellent pain and light touch sensation. In addition to that, two point discrimination test was ranged between 3 to $6 \mathrm{~mm}$, that means patients had no postoperative alteration or disturbance of their sensation in critical important area of the body i.e distal pulp of the fingers.

In their early report, Atasoy and associates claimed that 56 of 61 patients had normal sensation, however, a following study found hypoesthesia or dysthesia in 7 of 10 patients with volar flaps ${ }^{10}$.

We did not noticed any cold intolerance in our patients and this is attributed to preservation of blood supply to $\mathrm{V}-\mathrm{Y}$ rotation advancement flap since any cut of blood vessels can lead to increase incidence of cold intolerance.

Lastly, no obvious nail deformity was seen in those patients with digital amputation distal to Ishikawa II (apart from one patient), it's believed that undue tension on closure of volar triangular flap at tip of finger increase risk of hook nail deformity or parrot beak nail deformity; while with using the V-Y rotation advancement flap there is no tension on the site of closure, this might explain the low incidence of nail deformity seen in our study.

Mahdi H Abood and Amer S Daood did a comparative study of the supraperiosteal and the subperiosteal dissection in the $\mathrm{V}-\mathrm{Y}$ advancement (Atasoy) flap for the 
management of fingertip injury. Thirteen patients included in their study, 7 patients were reconstructed by the new modification of Atasoy (subperiosteal) flap and 6 patients by the classical Atasoy flap. The results showed that new modification of Atasoy flap improves flap viability, sensibility and aesthetic results. Their results may be attributed to the preservation of the fibrous septa of the pulp space and avoiding injury to the vessels and nerves by passing subperiosteal in the flap dissection ${ }^{14}$.
Conclusion and recommendations: V-Y rotation advancement flap is simple, quick, single stage operation that is optimum for surgical reconstruction of any plane fingertip injury. It provides a good contour of finger pulp while preserve the length of the finger with no postoperative sensory alteration or cold intolerance. It protected joint motion by not necessitating any splint. It also has acceptable postoperative fingertip appearance.

\section{References}

1. Steven L. Moran, William P. Cooney, III. Master techniques in orthopedic surgery : soft tissue surgery, 1st ed., Wolters Kluwer, Lippincott Williams and Wilkins, Philadelphia, 2009; pp. 246-247.

2. Achilleas thoma, Larisa Kristine Vartija. Making the V-Y advancement flap safer in fingertip amputation, Can J plast surg, 2010; 18(4):e47-e49.

3. Charles H. Thorane. Grabb and smith's plastic surgery, 5th. Ed., Lippincott- Raven, Philadelphia,1997;pp. 835.

4. Nezih sunger, yuksel kankaya, kaya yildiz. Bilateral V-Y rotation advancement flap for fingertip amputation, HAND, 2012;7:79-85.

5. Leo M.Rozmaryn. fingertip injuries: Diagnosis, Management and reconstruction, 1st ed., springer, New York,2015;pp.6-83-101.

6. Edward A. Jackson. The V-Y plasty in the treatment of fingertip amputation, American family physician, 2001;64(3):455-458.

7. Jeffrey E. Janis. Essential of plastic surgery, 2nd ed., CRC press, New York, 2014 ; pp. 812 .

8. Scott w. wolfe, Robert N. Hotchkiss, William C. Pedrerson, Scott H. Kozin. Green's operative hand surgery, Sixth ed., Elsevier, philadilphia, 2011;pp. 1888.

9. Joseph G. McCarthy, Robert D. Galiano, Sean G. Boutros. Current therapy in plastic surgery, 1st ed., Saunders Elsevier, Philadelphia, 2006 ; pp.556.

10. Scott W. Wolfe, Robert N. Hotchkiss, William C. Pedrson, Scott H. Kozin, Mark S. Cohen. Green's operative hand surgery, seventh ed., Elservier, Philadelphia, 2017; pp. 1717-1713.

11. Terri M. Skirven, A. Lee Osterman, Jane M. Fedorczyk, Peter C. Amadio. Rehabilitation of the hand and upper extremity, Sixth ed. , Elsevier Mosby, philadelphia, 2011 ; pp. 259.

12. Ross D. Farhadieh, Neil W. Bulstrode, Sabrina Cuguo. Plastic and reconstructive surgery: Approaches and technique, 1st ed., Wiley Black well, UK, 2015; PP. 688.

13. Yeo C J, Sebastian S J,Chong A K S. Fingertip injuries , Singapore Med J, 2015;52(1):78-86.

14. Mahdi H Abood, Amer S Daood. A comparative study of the supraperiosteal and the subperiosteal dissection in the V-Y advancement (Atasoy) flap for the management of fingertip injury: Basrah Journal of Surgery, 2007;13(1):1-11. 